\title{
A terahertz and infrared sensitive photomultiplier tube with a fieldmixing photocathode
}

\author{
Lange, Simon Lehnskov; Kabir Noori, Narwan; Kawai, Naoya; Jepsen, Peter Uhd
}

Published in:

Proceedings of $45<$ sup $>$ th $</$ sup $>$ International Conference on Infrared, Millimeter, and Terahertz Waves

Link to article, DOI:

10.1109/IRMMW-THz46771.2020.9370591

Publication date:

2020

Document Version

Publisher's PDF, also known as Version of record

Link back to DTU Orbit

Citation (APA):

Lange, S. L., Kabir Noori, N., Kawai, N., \& Jepsen, P. U. (2020). A terahertz and infrared sensitive photomultiplier tube with a fieldmixing photocathode. In Proceedings of 45 International Conference on Infrared, Millimeter, and Terahertz Waves [9370591] IEEE. International Conference on Infrared, Millimeter and Terahertz Waves https://doi.org/10.1109/IRMMW-THz46771.2020.9370591

\section{General rights}

Copyright and moral rights for the publications made accessible in the public portal are retained by the authors and/or other copyright owners and it is a condition of accessing publications that users recognise and abide by the legal requirements associated with these rights.

- Users may download and print one copy of any publication from the public portal for the purpose of private study or research.

- You may not further distribute the material or use it for any profit-making activity or commercial gain

- You may freely distribute the URL identifying the publication in the public portal 


\title{
A terahertz and infrared sensitive photomultiplier tube with a field- mixing photocathode
}

\author{
Simon L. Lange ${ }^{1}$, Narwan Kabir Noori ${ }^{1}$, Naoya Kawai ${ }^{2}$ and Peter U. Jepsen ${ }^{1}$ \\ ${ }^{1}$ DTU Fotonik, Technical University of Denmark, DK-2800 Kgs. Lyngby, Denmark \\ ${ }^{2}$ Department 22, Manufacturing \#2, Electron Tube Division, Hamamatsu Photonics K.K., Japan
}

\begin{abstract}
In this work, we present a photomultiplier tube (PMT) with a metasurface photocathode that is based on ultrafast field emission (FE) from incident terahertz (THz)- and infrared (IR) light. We mix the incident electric field with the electric field from an electronic source to decrease the PMT detection threshold. Due to the pronounced non-linearity of FE, this approach allows for extremely sensitive light detection - possibly down to few or even single photon level across the entire THz- and IR frequency range.
\end{abstract}

\section{INTRODUCTION}

$\mathrm{I}$ N 2019, we introduced a novel class of PMTs with light detection sensitivity in the entire THz- and IR frequency range [1]. The PMT concept is based on a metasurface photocathode that emits electrons into vacuum as a result of ultrafast FE, which is illustrated in Fig. 1a and 1b. In contrast to conventional photocathodes operated by the photoelectric effect from single photons, FE photocathodes are not limited in use by the work function of the photocathode material. Instead, the metasurface design concentrates the electromagnetic (EM) field of the incident light on to discrete, sharp metal emission tips. The concentration process is linear in the EM field, and it is therefore possible to collect the field from a large number of photons to enable FE from materials with a much larger work functions than the energy of individual photons.

\section{RESULTS}

FE requires electric fields on the order of $\mathrm{V} / \mathrm{nm}$ to be effective. We have previously shown that it is feasible to use metasurfaces obtain such extreme field strengths on the emission tips in the $\mathrm{THz}$ range starting from as low as $20 \mathrm{kV} / \mathrm{cm}$ incident field, corresponding to approximately $10^{10}$ photons at $0.5 \mathrm{THz}$. In this work, we demonstrate a metasurface concept that potentially decreases this number to a few- or even single photons.

Fig. 1c shows a SEM micrograph of the metasurface, with an optical microscope image of a single dipole antenna element from the metasurface shown in Fig. 1d and an outline of the operational principle in the inset in Fig. 1e. Each antenna element concentrates the incident EM field onto its two tips. Opposite of each tip, a bias line is introduced which is held at a higher potential than the antenna using an electronic source. The electronic bias enables FE, which is then modulated in amplitude by the field contribution from the incident light. Based on the Fowler-Nordheim FE equation, this modulation can be expressed as

$$
\frac{d J}{d E_{\text {light }}}=\frac{a}{\Phi}\left(2 E_{\text {bias }}+2 E_{\text {light }}+b \Phi^{\frac{3}{2}}\right) \exp \left(-\frac{b \Phi^{\frac{3}{2}}}{E_{\text {bias }}+E_{\text {light }}}\right)
$$

where $J$ is the emission current density, $E_{\text {bias }}$ is the electric field due to the electronic bias, $a$ and $b$ are constants, $\Phi$ is the emitter work function, $E_{\text {light }}$ is the electric field from the incident light and $d J / d E_{\text {light }}$ is the relative change in the emission current density established by $E_{\text {bias }}$ due to the influence of $E_{\text {light }}$. Since PMTs can detect changes in the emission current down to a single electron, one can by careful tuning of $E_{\text {bias }}$ allow for detection of extremely small values of $E_{\text {light }}$.
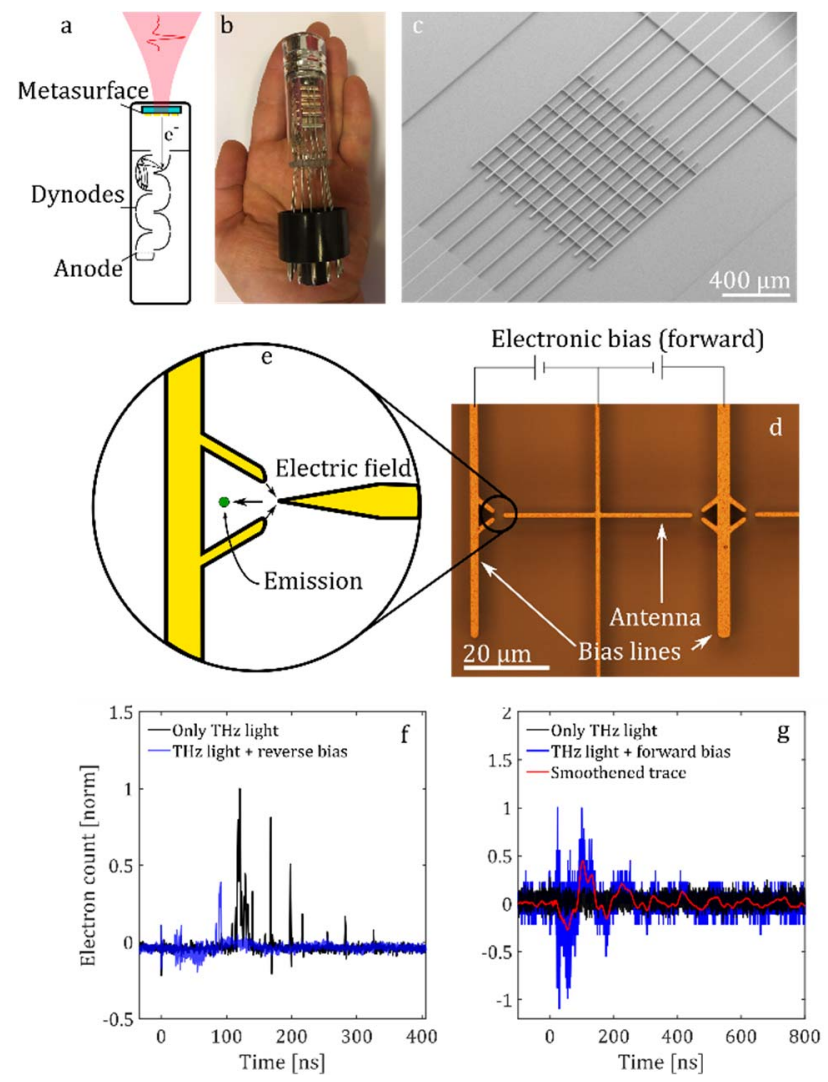

Fig. 1 | (a) PMT principle. (b) Actual PMT. (c) SEM micrograph of the electronically biased metasurface. A substrate etch is employed to avoid dielectric breakdown around the antenna tips. (d) Optical microscope image of a single antenna and bias lines. (e) Outline of the emission principle from the applied bias and the incident EM field. (f) Experimental data showing a decrease in emission when using reverse bias. (g) Experimental data showing how the application of the bias enables the detection of an otherwise undetectable field.

Fig. $1 \mathrm{~g}$ shows the result of an experiment that proofs the principle, where emitted electrons are recorded in a time-offlight electron spectrometer. $E_{\text {light }}$ is too weak to emit electrons from the metasurface, but when $E_{\text {bias }}$ is applied, the addition of the fields allow for electron emission. Fig. If shows the opposite situation where $E_{\text {light }}$ is emits electrons by itself. By reversing the sign of $E_{\text {bias }}$, the emission is heavily suppressed - these two situations are the principle for a PMT with a very large dynamic range.

\section{REFERENCES}

[1]. S. L. Lange, N. Kawai and P. U. Jepsen, "A photomultiplier tube with sensitivity in the entire terahertz- and infrared frequency range," IRMMW-THz conference, September, 2019 